\title{
EXPLORING MOBILITY AND SOCIAL MEDIA INTEGRATION IN AN ON-DEMAND ERP SYSTEM USING SAP BUSINESS BYDESIGN AS AN EXAMPLE
}

\author{
Karl E. Kurbel, European University Viadrina, wisek@europa-uni.de \\ Dawid Nowak, European University Viadrina, danowak@europa-uni.de
}

\begin{abstract}
Social media and enterprise mobility play an increasingly important role in business. This paper examines if and how social media can be integrated in an on-demand ERP environment, and identifies opportunities to enhance and adapt ERP functionality for mobile business users. Our exploratory study uses SAP Business ByDesign as an example. Special attention is paid to the requirements and challenges when expanding the functionality of this ondemand ERP system. Examples are provided, demonstrating the approach and the tools used to integrate screen elements and develop mobile applications. Our investigation shows that integrating social media and mobility is feasible, although an on-demand system does not provide the same extent of customization features as an onpremise system does. New approaches and customization tools dedicated to on-demand software are required.
\end{abstract}

Keywords: Enterprise Mobility, Enterprise Social Networking, SAP Business ByDesign, and ERP as a Service

\section{INTRODUCTION}

Reliable mobile access to business data is a key requirement for today's ERP systems. Due to more employees working outside of a traditional office environment, mobile devices have become important business tools. Mobility also plays a crucial role in the effective allocation of human resources [18]. In order to better organize their work, as well as save time and money while working outside the office, workers need access to business applications and corporate communication tools. Unified communications as well as advances in wireless technology have created opportunities for companies to incorporate more mobility.

Just as advances in mobile technology are changing where and when employees work, the popularity of social media is influencing how employees communicate with the customer and with each other. Increasingly, online collaboration networks are being used for business communication. Social networks, which are primarily dedicated to building online communities, have become favored marketing tools [4, 20, 33]. They are also used to generate publicity for a company.

Social networking for business focuses on the relations among people who share the same business interests. Many companies implement social networks to promote collaboration among their employees [6] by simplifying communication between workers and supporting the exchange of information and ideas [1]. Business social networks can also be used for circulating files, such as learning materials, within the company, or for exchanging project information between internal and external team members (e.g. company, customer and subcontractor employees) [2, 31]. While some companies use existing social networks (such as Twitter), others build their own internal community system (IBM) [11].

For most companies, incorporating mobile tools into routine business processes is not new, but the impact of mobility on business software is growing. Both mobile technology and social media have to be considered in the design of information systems, to allow for integration of the variety of mobile devices and social media platforms available today. This is particularly true for ERP systems, which constitute the information systems backbone of most companies. The surveys conducted by [5,7,19] predict that, in the coming years, market requirements will cause ERP solutions to move towards mobility and social media. Business software developers need to address the problem of compatibility in response to the large number of mobile devices currently on the market, with various system platforms and hardware requirements $[10,21]$.

However, today's ERP systems are not only traditional on-site systems, installed at the customer's location, but also so-called "on-demand systems," installed outside the company's premises and delivered to the customer "as a service" (aaS) [3]. Industry forecasts (e.g. [8]) indicate that this software delivery model will play an outstanding 


\section{Issues in Information Systems \\ Volume 14, Issue 1, pp.421-430, 2013}

role in the future of ERP systems. Therefore, on-demand ERP systems offered as a service need to support integration with community networks and mobile solutions.

\section{RESEARCH APPROACH}

In this paper, we analyze how social media can be incorporated into the environment of existing on-demand ERP systems, and how ERP-related content can be delivered to mobile devices. As the object of our exploratory study, we use an on-demand system provided by the market leader in business software: SAP Business ByDesign. (A common, yet not officially endorsed abbreviation of Business ByDesign is ByD.)

To achieve our objective, we follow a construction-oriented research approach [17, 34]. In construction-oriented research, scientists develop new insights by creating and proving new concepts, as it is common in the engineering sciences [15]. This approach includes exploratory research and often, the development of a prototype to demonstrate the feasibility of the underlying concepts $[13,15,34]$.

This approach was chosen because the research field is new and our study attempts to answer questions regarding the feasibility and usability of the concept. Using prototyping [13], we strive to demonstrate the feasibility of integrating social networks and mobile features into on-demand ERP systems and substantiate that the concept has potential for future developments.

The prototype solutions were developed and integrated into the on-demand ERP system. In our research, we focus on three different scenarios to test and evaluate the implemented solutions. In the first scenario, the social network Twitter is integrated in the main work center of Business ByDesign to allow employees to exchange companyinternal information. The second scenario focuses on the integration of Facebook in the dispatching process to simplify the communication between the customers and company employees. Underlying the third scenario is a mobile application for the presentation of sales reports on mobile devices.

The paper is organized as follows: The next section describes different technological approaches supported by Business ByDesign for adapting and expanding the system's functionality and user interface. These features are different from those available for typical on-site systems. The subsequent section focuses on the integration of social media into the user's ByD workplace, using Twitter and Facebook as examples. Afterwards, in the fifth section, we examine how on-demand ERP functionality can be deployed to a variety of mobile devices and provided to mobile users. The usability of the presented prototype solutions is evaluated in the sixth section. In the last section, our findings are summarized, and an outlook to future research is given.

\section{AVAILABLE FEATURES TO ADAPT SAP BUSINESS BYDESIGN}

Integrating social media and supporting enterprise mobility through a wide range of mobile devices require adaptation of the ERP system. On-demand systems cannot be customized in the same way as conventional onpremise systems. Because of the multitenant architecture, the vendor will not allow individual clients to modify the system's code to their needs. Therefore, different techniques have to be applied, depending on the customization options supported and provided by the vendor [16].

In SAP Business ByDesign, a number of changes can be accomplished with the help of metadata or add-ons. The latter can be integrated via so-called expansion points that are built into the core application. The majority of changes concerning the look and feel or the functionality of the software can be carried out in this way [16].

Business ByDesign was designed as a flexible solution that allows for additional services and applications required for a particular company's business processes. This is an interface-oriented approach, based on Microsoft Silverlight technology [10]. It allows users with administrative rights (so-called key users) to compose highly customized interfaces (including individual interface elements and composition themes). Key users may employ personalization tools embedded directly in ByD and a software development kit (SDK) [27]. The SDK is part of Business ByDesign Studio, an integrated development environment (IDE) based on Microsoft Visual Studio [10]. It allows the user to create and test applications (apps, add-ons) that are compatible with the natural environment of the system. 


\section{Issues in Information Systems \\ Volume 14, Issue 1, pp.421-430, 2013}

Today, many users require access to external, web-based data and programs for their work. Key users can integrate those sources in the user interface. ByD enables web services (e.g. Google Maps, Twitter, etc.) to be embedded directly into the system environment and data sources on the Internet to be accessed through mashups [24, 28].

By including web services and mashups in the user interface, web-based information is retrieved in a controlled manner and presented on the user's screen. Web services and mashups can be anchored to a custom screen layout according to the customer's requirements.

As mobile devices play an increasingly important role for business users, ByD supports a wide variety of devices and platforms. Based on design patterns [14], Business ByDesign Studio allows key users to freely create user interfaces, reports and forms that can be adapted to most output devices [26]. The SDK also supports the creation of so-called composite applications [22]. Composite applications reuse existing software components, combining them to support cross-functional processes [14]. New solutions can be created without writing new code. Using composite applications, a company can adapt to changes faster, which would otherwise require the development of new software and thus incur a higher cost.

In order to enable Business ByDesign users to easily expand the standard functionality, SAP introduced the SAP Store - an online commercial platform where users can purchase selected applications. One part of the store is dedicated to mobile apps. All customers using Business ByDesign have access to the store. They can visit the store directly from inside the ByD system.

The store's business model is similar to the model introduced by Apple to sell dedicated applications for the iPhone and iPad. The store allows users to search for available applications provided by SAP and SAP partners, as well as to test the applications before buying to examine the compatibility with their system [10].

\section{INTEGRATING SOCIAL MEDIA}

In this section, we investigate how social media can be integrated with the Business ByDesign system in a way that these media are immediately available inside the system. Our examples show how this integration creates value.

Examples of social media and other services supporting business processes and tasks include:

- Twitter: Exchange of brief information between employees of a company concerning internal affairs, e.g. project meetings, board meetings, etc.

- Facebook: Information exchange with customers about individual products or processes. Support/supplementation of CRM processes.

- Google: Search for data directly in the ERP system environment.

- Xing: Support of human resources processes, in particular the recruitment process. Exchange/update of employee information.

Each of the above platforms requires users to have individual accounts, so that the author of a specific message can be identified. These platforms also make it possible to build user groups for a particular area of interest and allow users to exchange messages with the group members.

Because of the pattern-based ByD user interface, the above-mentioned services can be adopted into SAP Business ByDesign. Users with administrative rights may adapt/configure certain screen elements, altering them to match the needs of the company. For example, a screen element can be configured with the help of the system's adaptive tools to provide social media integration as a new service.

In order to add a new service, the particular screen element responsible for the desired function must be activated. Mashups are useful tools for accessing external services and data online. A mashup is a screen element that allows communication with a web service. It presents the service's elements as an integral part of the ERP system's screen.

Due to the diversity of online services, different mashup categories can be identified. They can be applied to different integration tasks [23]. To integrate online services, it is possible to use preconfigured mashups available 


\section{Issues in Information Systems \\ Volume 14, Issue 1, pp.421-430, 2013}

within the system. In case the available mashups are not sufficient for the purpose, adding a new mashup that performs the required functions can create an additional user interface element.

Only ByD key users may integrate new user interface elements, as only they are allowed to edit and change the composition of individual screens of the ERP system for the entire company. Using personalization tools, a key user can define a new mashup. To configure the mashup, script code has to be written. Many preconfigured scripts that enable the integration of nested applications into browser-based systems are also available, e.g. on the Google Gadgets website [9]. Once created, a mashup can be activated on certain screens.

Figure 1 presents a Twitter mashup, integrated into the Business ByDesign environment. Assuming that the application is used to exchange information among employees, every time a user logs into the system, they see the recent messages that were posted by their colleagues. Thus, the application improves the information flow within the company.

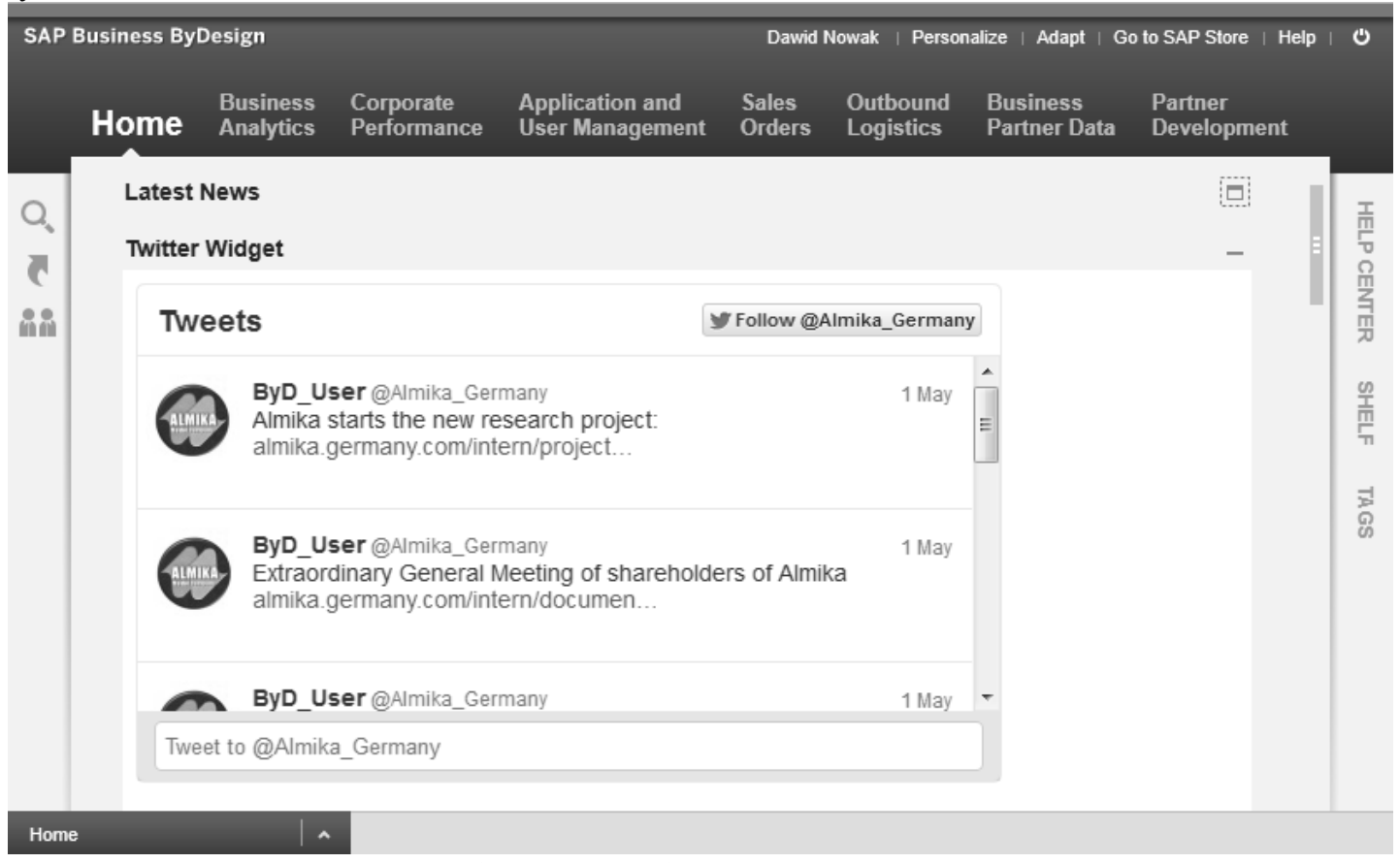

Figure 1. Twitter Mashup Integrated into a Business ByDesign User Interface

Mashups defined by key users can also be integrated into certain business processes to support the communication between customers and employees. Integrating an online sales process with a social network, e.g. Facebook, can significantly simplify the information flow between customers and the sales department. Just as is the case with the traditional sales process, this information exchange should be registered in the ERP system to be available later.

A Facebook mashup supporting real-time interaction between an employee working with the ERP system and a customer is illustrated in figure 2. The mashup serves as an integration tool between the social network (in this case, Facebook) and the environment of the ERP system. It was implemented in a certain step of the dispatching process. In the customer master data, an additional field is required to store the customer's Facebook address.

In the process of dispatching the sales order no. 1663, relevant information concerning the current state of the order is sent from the ERP system directly (through a Facebook message plugin) to the customer's Facebook account. The customer receives the message in his or her Facebook message inbox, and can respond by sending feedback or asking a question. The dispatching department may react, based on the data provided by the customer, and change order parameters in the ERP system, etc.

Information exchanged through mashups should be archived in the same way as e-mail exchanges with customers are saved and attached to the order in the ERP system. 


\section{Issues in Information Systems}

Volume 14, Issue 1, pp.421-430, 2013

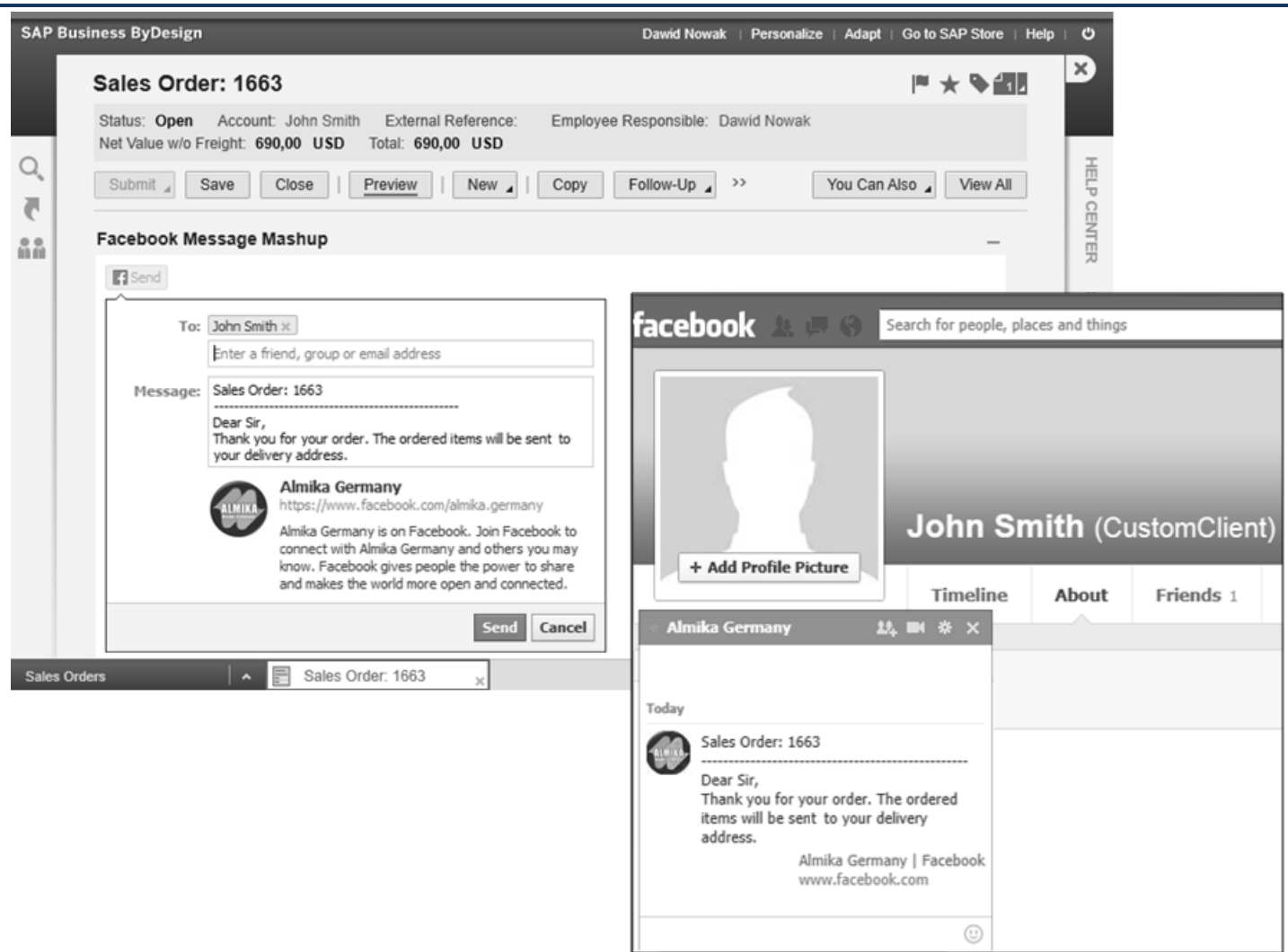

Figure 2. Facebook Service Integrated in a Business Process.

Other social services, such as Xing, can be integrated into the recruitment process or other HRM processes in a similar fashion. Information about a certain candidate or employee may then be exchanged between the online service and the ERP system.

To summarize, community networks connected with an ERP system can considerably improve communication between employees, customers and other stakeholders of a business process, as well as boost the flow of information within the company.

However, a major challenge of social media integration is the fact that business processes supported by ERP systems require structured data, while the information provided through social media is not structured. Therefore, the integration stage poses a problem, as the solution must assure that both non-structured exchange of information is possible and data relevant to a given business process in the ERP system is explicitly extracted.

\section{SUPPORTING ENTERPRISE MOBILITY}

In this section, we examine how on-demand ERP functionality can be provided to mobile users. This includes the question of deploying the content to a variety of mobile devices with different features and screen sizes.

With the increasing acceptance of mobile solutions among users, mobile business applications are rapidly gaining importance [30]. Mobile applications change the way work is completed, especially in daily business processes, and they help increase the productivity of remote workers [18]. The use of mobile applications requires management of mobile access, raising additional concerns regarding the security of business data [12, 25]. Considering the fact that an increasing number of mobile workers need access to current business information and processes, many companies are adopting mobile applications and providing their users with mobile access to their business systems. 


\section{Issues in Information Systems \\ Volume 14, Issue 1, pp.421-430, 2013}

As is the case for standard desktop applications, mobile applications must be compatible with the different operating systems typically found in mobile technology. Creating mobile versions of standard desktop applications usually requires programming. Mobile applications are in many ways different from their desktop counterparts. In many cases, the mobile version of an application does not include the same range of functionality that is offered by the full desktop version. Often the focus is only on certain parts of the business process, rather than addressing the process in its entirety.

Creating applications for mobile platforms presents both a programming and a design challenge. In order for information to fit the limited size and resolution of a mobile device [14], application developers must design user interfaces that can be adapted to the specific parameters of the mobile device.

On the other hand, high-end mobile devices equipped with additional items such as a camera, GPS system or touchscreen pose additional challenges, because they allow for technologically more advanced business solutions than those available for desktop systems.

While previously, customization of conventional on-site systems required making changes to the source code, customizing Business ByDesign is much simpler, but it is also limited. User interface elements as well as necessary business logic can be added by drag and drop, using preconfigured elements offered by the SDK. In this way, mobile applications can be added. Availability of composite applications can also significantly contribute to a simplification of the development process. Composite applications consist of reusable web services and are themselves reusable in subsequent development projects.

Mobile applications based on SAP Business ByDesign can be created using the software development kit (SDK) of Business ByDesign Studio [10, 29]. Via ByD Studio, SAP allows partners to create applications for mobile use. As is the case with on-site system solutions, certified partners may create dedicated applications that expand the functionality of the system. Currently, SAP provides the SDK only to certified partners, thus ensuring a certain standard for mobile applications. However, the market for mobile add-ons to Business ByDesign is growing, and the number of certified partners is also rising.

The need to support a variety of mobile devices is significantly supported by the pattern-based development approach. Using patterns, the user interface code is separated from the rest of the system. Instead of creating a new user interface for each platform from scratch, the same user interface model can be interpreted natively for many different platforms [10]. Therefore, additional user interfaces may be created for a variety of mobile devices and easily embedded without compromising the rest of the system. For the user, this means that they can access Business ByDesign functionality through their preferred mobile device and platform. ByD currently supports five mobile platforms (smartphones) and offers dedicated applications for tools based on multi-touch technology (tablets) [30].

On-demand systems develop alongside other technological trends. As more users become interested in mobile applications, the number of certified application developers also increases, offering customers an even greater selection of mobile solutions [30]. Some of these applications expand general ERP system functionality, while others are dedicated to a specific business branch.

To illustrate the business potential of mobile applications using Business ByDesign, we developed a demo application with the help of ByD Studio. This application creates a sales report for display on mobile devices. The fictitious enterprise was previously configured in the Business ByDesign system. The screen of the mobile device shows a diagram depicting the income from last year's sales, divided into months. This diagram is created within the Business ByDesign environment and, when it is to be displayed on a mobile device, adapted to the properties and constraints of the device. 


\section{Issues in Information Systems \\ Volume 14, Issue 1, pp.421-430, 2013}

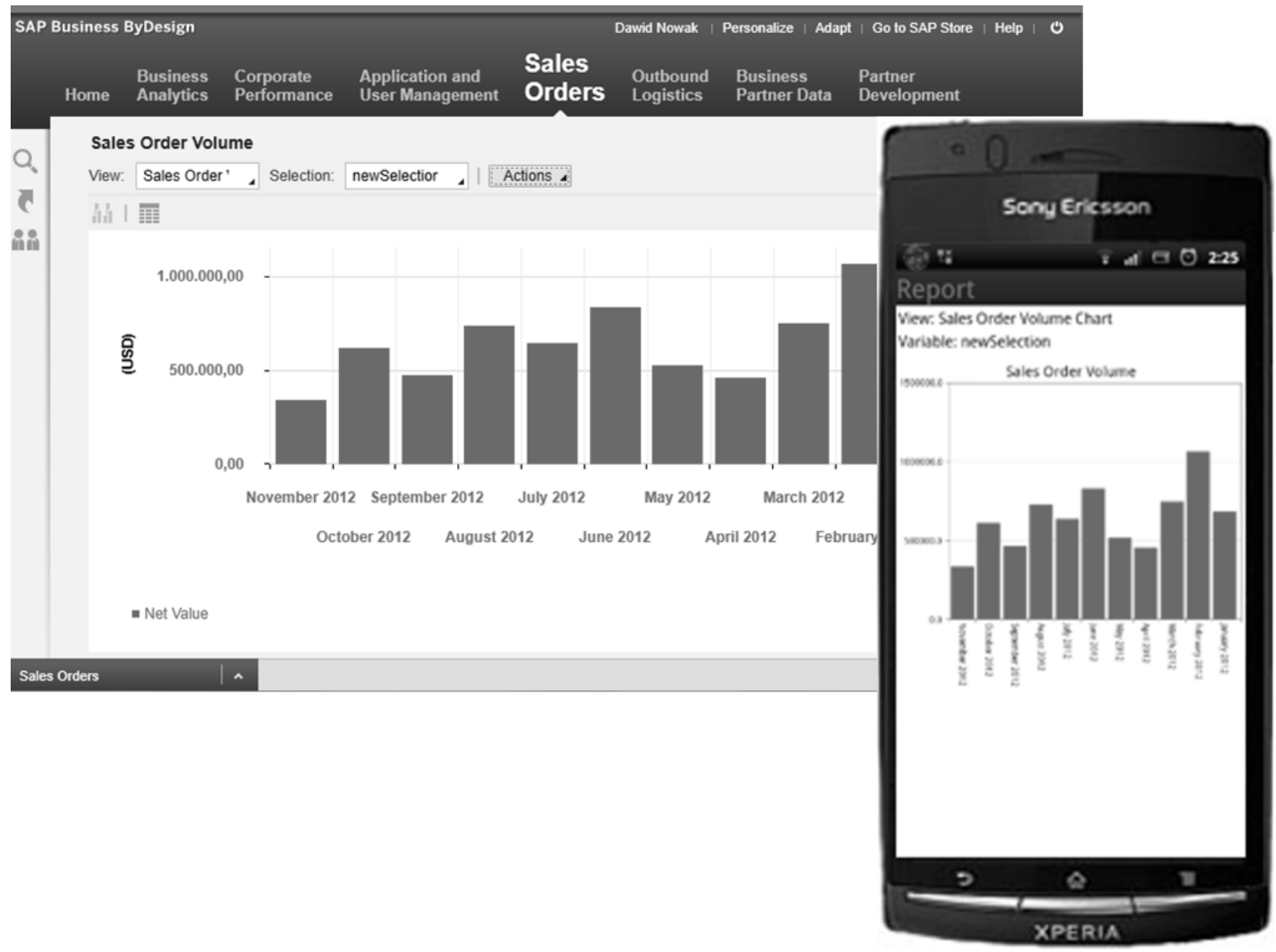

Figure 3. Mobile Application Developed with Business ByDesign Studio SDK.

The main application was designed by resorting to preconfigured user interface elements available through the SDK [29]. These elements were connected to the required business objects that are equipped with the business logic. The diagram was created in the main ERP system and is now invoked by the mobile application.

This mobile demo application was designed to run on an Android device. However, thanks to the flexible patternbased user interface of ByDesign Business Studio, the application can easily be adapted to run on other mobile platforms.

Once the user has installed the application on a mobile device (such as a smartphone), he or she can run it. When the user is logged on to the system, and the application has been started, the diagram presenting sales order figures is displayed on the screen as shown in figure 3 . The diagram is automatically adapted to the screen size of the device. An employee in the field, for example, can access the sales data at any time and/or place whenever and wherever needed.

It should be noted that this application was only created for demonstration purposes, i.e. to show how a mobile user can access ERP content provided by SAP Business ByDesign as a service. It is not available as a mobile app for ByD users from the SAP Store.

\section{EVALUATION}

Our research and prototypical developments have shown that social network and mobility solutions can be integrated in an ERP system, even if this system is an on-demand system offered as a service. In this section, we point out some of the benefits of the solutions described in the previous sections.

The Twitter-based solution implemented in the first scenario (Twitter mashup) supports immediate information exchange between employees inside the company. Every time a new message is posted using the Twitter mashup, it 


\section{Issues in Information Systems \\ Volume 14, Issue 1, pp.421-430, 2013}

is automatically available on the users' screens in the entire company at the same time. Each system user can comment on the posted topic directly from their ERP system, track comments by others and participate in discussions involving other employees. Standard communication tools (such as e-mail) implemented in ERP systems do not allow for discussion or thread tracking and require the user to continuously switch between screens in order to read the messages. A microblogging technology (e.g. Twitter) embedded in the normal work environment (i.e. the ERP system) creates opportunities for faster and simpler information and opinion exchange between employees.

Similarly, the integration of Facebook in business processes helps to facilitate information exchange between customers and the sales department. Due to the fact that many individuals frequently visit their Facebook profile [32], business communication (between customers and the company) through this channel can be more effective than through traditional e-mail. Because incoming messages are accessible directly from the user profile, the customer does not need to log on to their e-mail account and check their inbox. Since the user sees whether the sender is online, they can chat in real-time - speeding up the communication. In contrast, exchanging information via e-mail takes much longer.

In the third scenario, the mobile application gives employees direct access to real-time information stored in the main system anytime and anywhere. Using the mobile application, a user outside the company's office may still view up-to-date reports. Based on up-to-date information, users can make the right decisions. Thanks to mobile access to ERP data, the decision-making process can be simplified and improved. Employees do not need to travel to their office every time they need a new report.

\section{CONCLUSIONS}

This paper presented the possibility of integrating social media into the environment of an on-demand ERP system and identified opportunities for adapting the functionality of these systems for mobile devices. Our exploratory study used SAP Business ByDesign as an example of an on-demand ERP system. Within the ByD environment, several test solutions were implemented with the help of the available customization features and the ByD Studio software development kit (SDK).

We showed that an on-demand ERP system allows social media and mobile applications to be integrated. Access to social networks can be embedded in the system's user interface. With the help of preconfigured user interface elements and mashups, key users may integrate web services into the system environment. In this way, the company's business processes can be enhanced through easy communication with customers or employees, and the information flow within the company is boosted.

Providing mobile applications and on-demand ERP functionality to mobile users was also demonstrated. By making preconfigured system elements (e.g. user interface elements, business objects) directly available in the development environment of Business ByDesign Studio, the process of application development has been significantly simplified. New mobile solutions can now be created more quickly and efficiently, to enhance the ERP system's default functionality. Easy access for end users to these solutions is crucial.

Introducing a commercial platform for trading applications connected with $\mathrm{ByD}$, the $\mathrm{SAP}$ Store, is an innovative step by SAP in the field of ERP system modularity and expansion. The store can be directly accessed from the ERP system. Customers may try out the applications before making the final decision to buy. Since the applications traded on this platform have to meet certain standards and conventions, they are supposed to run in the customer's environment without further customizing.

The presented solutions are just a few examples of how social networks and mobile applications can be included in an ERP environment. New solutions to ERP problems can also be integrated with the help of the adaptation features described in this paper.

Expanding the functionality of Business ByDesign has become very popular among SAP partners. A growing interest in the development of mobile applications can be observed, which is directly reflected in the increasing number of certified SAP partners on the store. 


\section{Issues in Information Systems \\ Volume 14, Issue 1, pp.421-430, 2013}

SAP Business ByDesign is one of many on-demand ERP systems offered today as a service. Since ERP systems from different vendors vary in many respects - e.g. architecture, user interface technology, software platform further studies are required to investigate other on-demand systems with respect to their adaptability to the requirements of mobile platforms and the integration of social networks. In future research, common features of the different adaptation approaches should be extracted to be able to generalize the insights and create a framework for social media and mobility integration into on-demand ERP systems.

\section{REFERENCES}

[1] Back, A., Gronau, N. and Tochtermann, K., Web 2.0 in der Unternehmenspraxis: Grundlagen, Fallstudien und Trends zum Einsatz von Social Software, Oldenbourg, 2008.

[2] Bingham, T., Conner, M. and Pink, D. H., The New Social Learning: A Guide to Transforming Organizations Through Social Media, San Francisco: ASTD \& Berrett-Koehler, 2010.

[3] Carraro, G., and Chong, F., "Software as a Service (SaaS): An Enterprise Perspective," Microsoft Corporation, October 2006. [Online]. Available: http://msdn.microsoft.com/en-us/library/aa905332.aspx. [Accessed 22 August 2012].

[4] Chester, J., Butler, M., and Butler, D., Enterprise Social Networking and Collaboration, Martin Butler Research, 2010.

[5] Deloitte Ltd., "Technology, Media \& Telecommunications Predictions 2013," Deloitte, London, 2013.

[6] DiMicco, J., Millen, D., Geyer, W., Dugan, C., Brownholtz B., and Muller, M., "Motivations for social networking at work," in Proceedings of the 2008 ACM conference on Computer supported cooperative work, New York, 2008.

[7] Gartner Inc., "Gartner Identifies the Top 10 Strategic Technology Trends for 2013," Gartner, 23 October 2012. [Online]. Available: http://www.gartner.com/newsroom/id/2209615. [Accessed 3 February 2013].

[8] Gartner Inc., "Gartner Says Cloud and CRM Will Drive Enterprise Software Spending in 2013 and 2014," Gartner, 5 March 2013. [Online]. Available: http://www.gartner.com/newsroom/id/2358015. [Accessed 14 March 2013].

[9] Google Inc., "Google Gadgets," Google, 2008. [Online]. Available: http://www.google.com/ig/directory?synd $=$ open. [Accessed 6 February 2013].

[10] Hufgard A., and Krüger, S., "SAP Business ByDesign Geschäftsprozesse, Technologie und Implementierung anschaulich erklärt," SAP Press, Bonn, 2012.

[11] IBM, "IBM Beehive," IBM, 1 January 2008. [Online]. Available: http://www-01.ibm.com/software/ucd/ gallery/beehive_research.html. [Accessed 2 February 2013].

[12] IDC Central Europe GmbH, "Managing Mobile Enterprises," September 2012. [Online]. Available: www.computerwoche.de/ueb/19107. [Accessed 9 March 2013].

[13] Krcmar, H. "Current Research and Practice in Information Systems in Germany", Proceedings of the Third European Conference on Information System ECIS '95, pp. 1295-1297, Athens, Greece: June 1-3 1995.

[14] Kurbel, K. E., The Making of Information Systems - Software Engineering and Management in a Globalized World, Berlin, Heidelberg: Springer, 2008.

[15] Kurbel, K. E., Krybus, I. and Stankov, I., "Reviewing Criteria of Information Systems, Computer Science and Engineering Journals," Journal of Computer Information Systems, vol. 51, no. 4, pp. 74-80, 2011.

[16] Kurbel, K. E., and Nowak, D., "Customization of On-demand ERP Software Using SAP Business ByDesign as an Example," in Innovation and Future of Enterprise Information Systems: ERP Future 2012 Conference, Salzburg, Austria, November 2012, Revised Papers, Lecture Notes in Information Systems and Organisation 4; Springer-Verlag, Berlin/Heidelberg, pp. 289-297, 2013.

[17] Lange, C. "Development and Status of the Information Systems / Wirtschaftsinformatik Discipline: An Interpretive Evaluation of Interviews with Renowned Researchers: Part I - Research Objectives and Method". ICB-Research Report No 2, University Duisburg-Essen, 2005.

[18] Maan, J., "A Connected Enterprise-Transformation Through Mobility And Social Networks," International Journal of Managing Information Technology, vol. 4, no. 3, pp. 89-95, 2012. 


\section{Issues in Information Systems \\ Volume 14, Issue 1, pp.421-430, 2013}

[19] Martens, C., "Thoughts On The ERP Market As 2012 Shifts Into 2013," Forrester Ltd., 10 December 2012. [Online]. Available: http://blogs.forrester.com/china_martens/12-12-10-thoughts_on_the_erp_market_as_ 2012_shifts_into_2013. [Accessed 3 February 2013].

[20] Richter, D., Riemer, K. and vom Brocke, J., "Internet Social Networking," Business \& Information Systems Engineering, vol. 3, no. 2, pp. 89-101, 2011.

[21] SAP AG, "2013 IT Market Trends And Predictions," 1 February 2013. [Online]. Available: http://blogs.sap. com/innovation/industries/2013-it-market-trends-and-predictions-026226. [Accessed 15 February 2013].

[22] SAP AG, "Guiding Principles for Designing Composite Applications," SAP, 2011. [Online]. Available: https:/help.sap.com/saphelp_nwce10/helpdata/en/07/673a687c654787bef50b7b7430008d/content.htm. [Accessed 3 February 2013].

[23] SAP AG, "Mashup Categories," SAP, 2011. [Online]. Available: http://help.sap.com/saphelp_byd30/en/KTP/ Software-Components/01200615320100003379/WEKTRA_for_Work_Centers/CROSS_TOPICS/ MASHUPS/ESS_CON_MashupCategories.html. [Accessed 3 February 2013].

[24] SAP AG, "Mashups and Web Services," SAP, 2011. [Online]. Available: http://help.sap.com/saphelp_byd30/ en/KTP/Software-Components/01200615320100003379/SAP_BBD/Print_Files/PDF_FILES/FLEX_en.pdf. [Accessed 3 February 2013].

[25] SAP AG, "Mobile Anwendungen stärken Unternehmen - und wer stärkt das Management mobiler Anwendungen?," July 2012. [Online]. Available: http://www.computerwoche.de/fileserver/idgwpcw/files/ 2141.pdf. [Accessed 14 March 2013].

[26] SAP AG, "New Release of SAP ${ }^{\circledR}$ Business ByDesign" ${ }^{\mathrm{TM}}$ Solution Advances Cloud Computing Portfolio from SAP," 4 February 2011. [Online]. Available: http://www.sap.com/corporate-en/press.epx?PressID=14707. [Accessed 18 February 2013].

[27] SAP AG, "Personalization Quick Guide," SAP AG, 2011. [Online]. Available: http://help.sap.com/saphelp_ byd35/en/KTP/Software-Components/01200615320100003379/WEKTRA_for_Work_Centers/CROSS _ TOPICS/PERSONALIZATION/EndUser_Personalization/VQG_Personalization.html. [Accessed 3 Fébruary 2013].

[28] SAP AG, "SAP Business ByDesign Business Flexibility View," SAP, 2011. [Online]. Available: http:/help. sap.com/saphelp_byd30/en/KTP/Software-Components/01200615320100003379/SAP_BBD/Print_Files/PDF _FILES/FLEX_en.pdf. [Accessed 2 February 2013].

[29] SAP AG, "SAP Business ByDesign User Interface Guidelines," 31 July 2011. [Online]. Available: http://www.sapdesignguild.org/resources/ByD_UI_Styleguide_2012_FP35.pdf. [Accessed 14 March 2013].

[30] SAP AG, "SAP Store," SAP AG, 2013. [Online]. Available: https://store.sap.com/sap/cpa/repository/store/ Page.html. [Accessed 19 February 2012].

[31] Sinclaire, J. K. and Vogus, C. E., "Adoption of social networking sites: an exploratory adaptive structuration perspective for global organizations," Information Technology and Management, vol. 12, no. 4, pp. 293-314, 2011.

[32] Tam, D., "Facebook by the numbers: 1.06 billion monthly active users," CNET Inc., 30 January 2013. [Online]. Available: http://news.cnet.com/8301-1023_3-57566550-93/facebook-by-the-numbers-1.06-billionmonthly-active-users/. [Accessed 20 June 2013].

[33] Thackeray, R., Neiger, B. L., Hanson, C. L. and McKenzie, J. F., "Enhancing Promotional Strategies Within Social Marketing Programs: Use of Web 2.0 Social Media," Health Promotion Practice, pp. 338-343, 2008.

[34] Wilde, T., Hess, T. "Forschungsmethoden der Wirtschaftsinformatik - Eine empirische Untersuchung", Wirtschaftsinformatik, vol. 49, no. 4, pp. 280-287, 2007. 